\title{
Signaling Pathway in the Osmotic Resistance Induced by Angiotensin II AT2 Receptor Activation in Human Erythrocytes
}

\author{
Camila Cristina Guimarães-Nobre ${ }^{1,3}$, Evelyn Mendonça-Reis ${ }^{1,3}$, Luana Passinho- \\ da-Costa ${ }^{1,5}$, Leandro Miranda-Alves ${ }^{2,3,4}$, Clemilson Berto-Junior*1,2,3,5
}

\begin{abstract}
Background: Angiotensin II regulates blood volume via AT1 (AT1R) and AT2 (AT2R) receptors. As cell integrity is an important feature of mature erythrocyte, we sought to evaluate, in vitro, whether angiotensin II modulates resistance to hemolysis and the signaling pathway involved.

Methods: Human blood samples were collected and hemolysis assay and angiotensin II signaling pathway profiling in erythrocytes were done.

Results: Hemolysis assay created a hemolysis curve in presence of Ang II in several concentrations $\left(10^{-6} \mathrm{M}\right.$, $\left.10^{-8} \mathrm{M}, 10^{-10} \mathrm{M}, 10^{-12} \mathrm{M}\right)$. Angiotensin II demonstrated protective effect, both in osmotic stressed and physiological situations, by reducing hemolysis in $\mathrm{NaCl} 0.4 \%$ and $0.9 \%$. By adding receptors antagonists (losartan, AT1R antagonist and PD 123319, AT2R antagonist) and/or signaling modulators for AMPK, Akt/PI3K, p38 and PKC we showed the protective effect was enhanced with losartan and abolished with PD 123319. Also, we showed activation of $\mathrm{p} 38$ as well as PI3K/Akt pathways in this system.

Conclusions: Ang II protects human erythrocytes from hypo-osmotic conditions-induced hemolysis by activating AT2 receptors and triggering intracellular pathways.
\end{abstract}

Keywords: Angiotensin II, Erythrocyte, Osmotic fragility, Signaling pathway.

\section{Introduction}

Angiotensin II (Ang II) is an octapeptide belonging to renin-angiotensin-aldosterone system (RAS) and is responsible for ubiquitous actions in several tissues. Effects observed with Ang II occur by its binding in one of the two well-recognized receptors named AT1R and AT2R with also well-known signaling pathways (1). Ang II can act in cardiac system, central nervous system, thyroid glandule among others (2-4). Stimulated AT1R is described as an activator of diverse signaling pathways among several cell types: Gao and co-workers showed activation of ERK $1 / 2$ and p38 MAPK pathways when AT1R is activated in rat heart (5); in MCF-7 breast cancer cells, AT1R activates PI3-kinase/Akt pathway prompting survival (6); also, Ang II stimulates AMPActivated Protein Kinase (AMPK), inducing inflammation in atrial myocytes (7). AT2R shares approximately $34 \%$ amino acid sequence homologue with AT1R and the abundance increases in tissues under pathological conditions, where inflammation and tissue remodeling occur (8). However, in cardiovascular diseases, AT2R demonstrated

1: Grupo de Pesquisa em Fisiologia Eritróide - GPFisEri, Universidade Federal do Rio de Janeiro, Campus Macaé, Brazil.

2: Laboratório de Endocrinologia Experimental- LEEx, Instituto de Ciências Biomédicas, Universidade Federal do Rio de Janeiro, Brazil. 3: Programa de Pós-graduação em Endocrinologia, Faculdade de Medicina, Universidade Federal do Rio de Janeiro, Brazil.

4: Programa de Pós-graduação em Farmacologia e Química Medicinal, Instituto de Ciências Biomédicas, Universidade Federal do Rio de Janeiro, Brazil.

5: Faculdade de Farmácia, Universidade Federal do Rio de Janeiro, Campus Macaé, Brazil.

*Corresponding author: Clemilson Berto-Junior; Tel: + 552198081 3681; E-mail: clemijr@yahoo.com.br.

Received: 3 Mar, 2021; Accepted: 7 Apr, 2021 
a potential benefit, and in general, it seems to have an effect that counterbalances the response of AT1R (2).

A study by Saraiva et al. (2011) demonstrated the presence of Angiotensin receptors (AT1R, AT2R) in the erythrocyte membrane through western blotting (9). Considering the hemopoietic system, Kato and co-workers (2015) showed anemia in angiotensinogen knocked-out mice and this anemia was reverted by infusion of Ang II mediated by AT1R (10). Nevertheless, RAS modulates the levels of erythropoietin and increasing evidences suggests Ang II may be responsible for controlling red blood cells homeostasis (11). Red blood cells or erythrocytes are cells responsible primarily for gas transportation across the body, also participating in homeostasis and blood coagulation and nitric oxide production $(12,13)$.

For a long time, erythrocytes were considered "passive" cells being only capable of gas transport. Nowadays, increasing evidence suggest that erythrocytes possess a complexity of intracellular proteins playing sophisticated roles in physiological and pathophysiological processes. Although lacking of nucleus and other organelles, erythrocytes show several intracellular signaling proteins and second messengers answering binding of hormones and others molecules to cell surface receptors (14). Liu and coworkers (2016) demonstrated that AMPK is triggered after adenosine receptor 2B (ADORA2B) activation and this pathway is responsible for rise in 2,3 bisphosphoglycerate (2,3-BPG) production. In the same way, a non-metabolizable adenosine analog (NECA) was able to increase cAMP production in erythrocytes and $\mathrm{H} 89$, a specific potent PKA inhibitor, reverted the 2,3-BPG increased levels by NECA, ratifying the presence and crucial role of Gs/PKA signaling pathway (15). Also, Kuck et al. (2019) illustrated the important role of PI3K/Akt signaling in red blood cell deformability, this pathway being important for erythrocyte deformability (16).

Several pathways can influence the deformability of erythrocytes and their deformation capacity is essential for the performance of their functions and passage through blood vessels (17). An important method used to assess erythrocyte deformability is the osmotic fragility test (18), often used for the diagnosis of hereditary hemolytic diseases (19).

Angiotensin receptors such as AT1R, AT2R and MAS were already described in erythrocyte membrane (9). However, there is still a lack of current literature describing the role of these receptors in the physiological processes of erythrocytes and which signaling pathways are triggered by these receptors. Therefore, the relationship between angiotensin II signaling and low osmolarity stress in erythrocytes is investigated by using AT1 (losartan) and AT2 (PD123319) receptor antagonists to identify if angiotensin II modulates erythrocytes volume regulation and, if does, which signaling pathway is involved in this modulation.

\section{Materials and Methods Samples}

The collection of human blood was carried out after approval of the project by the Ethics Committee of the Federal University of Rio de Janeiro (Protocol 2.889.952) and the project is registered in Brazil platform under CAAE number 88140418.5.0000.5699. The study methodologies were in conformity with standards set by the Declaration of Helsinki and human subjects were informed about the study. Those who agreed to participate filled out the free informed consent form for collection of blood sample and subsequent use. Those with any hemoglobinopathies and those taking controlled medication were excluded. Blood samples were collected in anticoagulant tubes with EDTA by puncture of antecubital fossa. All experiments were performed on the same day of blood sample collection. 


\section{Hemolysis assay}

After blood collection, EDTA tubes were centrifuged for 10 minutes at approximately 1,500 rpm. The leukocyte and platelet layer were removed. Then, red blood cells (RBC) were washed with PBS (phosphate-buffered saline) three times (tubes were homogenized by inversion and centrifuged in the same parameters as above). RBC suspensions were submitted to increasing concentrations of sodium chloride $(0.1 \%-0.9 \%)$, followed by angiotensin II with $1 \%$ hematocrit, thus obtaining a final angiotensin II concentration of $10^{-6} \mathrm{M}, 10^{-8} \mathrm{M}, 10^{-10} \mathrm{M}, 10^{-12} \mathrm{M}$. Tubes were placed in a water bath for one hour, at $37^{\circ} \mathrm{C}$, and centrifuged at $3,000 \mathrm{~g}$ for 10 minutes. Supernatant was removed and pipetted into 96well plate. Reading was taken in an Elisa reader (Tecan GENios) at $540 \mathrm{~nm}$ absorbance.

\section{Signaling Pathway}

To assess possible pathways, the following substances were used: Losartan (AT1R antagonist), PD 123319 (AT2R antagonist), Wortmannin (PI3K inhibitor), AICAR (AMPK activator), AKT1/2 (AKT inhibitor), GO 6983 (PKC inhibitor) and SB 202190 (inhibitor of p38 MAPK). PD 123319, losartan, SB 202190 and GO 6983 were purchased from Med Chem Express and Akt $1 / 2$ inhibitor and wortmannin from Sigma Aldrich. Hemolysis assay has also been performed with: AT1R antagonist (losartan, $100 \mu \mathrm{M}$ ) or AT2R antagonist (PD 123319, $100 \mathrm{nM}$ ); addition of Akt $1 / 2$ inhibitor (1 $\mu \mathrm{M})$, Akt $1 / 2$ inhibitor + losartan, AICAR (1 $\mathrm{mM})$, AICAR (1 mM) + losartan; wortmannin $(10 \mu \mathrm{M})$, wortmannin + losartan; SB 202190 (100 nM), SB 202190 + losartan; GO 6983 $(50 \mathrm{nM}), \mathrm{GO} 6983$ + losartan. All those analyzes were performed, in order to assess angiotensin II signaling pathway profile in erythrocyte, using the osmotic stress concentration of $0.4 \% \mathrm{NaCl} .0 .1 \% \mathrm{NaCl}$ was used as a $100 \%$ hemolysis control, without adding any substance.

\section{Statistical analysis}

GraphPad Prism 5 was used to plot the graphs and to perform statistical analysis, with all data expressed as mean \pm SEM. For all experiments, an ANOVA with Tukey's posttest was used for analysis of the significant differences $(*$ for $\mathrm{p}<0.05$, $* *$ for $\mathrm{p}<0.01$ and $* * *$ for $\mathrm{p}<0.001$, when compared to control with a confidence interval of $95 \%$ ).

\section{Results}

Osmotic fragility test (OFT) was performed, in vitro, to evaluate the percentage of hemolysis in $0,1 \%$ to $0,9 \% \mathrm{NaCl}$ concentration. This change in osmotic milieu was accompanied by marked hemolysis in very low sodium chloride concentrations of $0.1,0.2,0.3$ and $0.4 \%$. We took $0.1 \%$ as $100 \%$ of hemolysis and compared with the amount of subsequent hemolysis (Fig. 1). When Ang II $10^{-12} \mathrm{M}$ was added to the media (Fig. 1A), there was a left shift of the curve with statistically significantly decreased hemolysis in $0.4,0.6$ and $0.9 \%$ $\mathrm{NaCl}$, from $88.87 \%, 14.15 \%$ and $13.04 \%$ (controls, respectively) to $46.53 \%, 10.84 \%$ and $9.55 \%$ (Ang II $10^{-12} \mathrm{M}$, respectively) compared to control curve. Angiotensin $10^{-10}$ $\mathrm{M}$ (Fig. 1B) showed protection at $0.4 \%, 0.6 \%$, $0.8 \%$ and also in $0.9 \% \mathrm{NaCl}$ concentrations, from $88.87 \%, 14.15 \%, 13.48 \%$ and $13.04 \%$ (controls, respectively) to $53.31 \%, 9.99 \%$, $9.61 \%$ and $8.56 \%$ (Ang II $10^{-10} \mathrm{M}$, respectively). At Ang II $10^{-8} \mathrm{M}$ and Ang II $10^{-}$ ${ }^{6} \mathrm{M}$ (Figs. $1 \mathrm{C}$ and $1 \mathrm{D}$ ), there was a strong protection against hemolysis in $0.4 \%$ of $\mathrm{NaCl}$ from $88.87 \%$ (for both controls) to $56.55 \%$ and $56.91 \%$, respectively, and to a lesser extent in $0.7 \%, 0.8 \%$ and $0.9 \% \mathrm{NaCl}$ from $11.33 \%$, $13.48 \%$ and $13.04 \%$ (for the three controls, respectively) to $8.18 \%, 9.15 \%$ and $8.21 \%$ in Ang II $10^{-8} \mathrm{M}$ and $7.60 \%, 9.98 \%$ and $7.71 \%$ in Ang II $10^{-6} \mathrm{M}$, respectively.

Osmotic fragility in $\mathrm{NaCl} 0.4 \%$ treated with the combination of angiotensin II (in all four concentrations) and losartan, a specific AT1R antagonist, showed an enhanced 

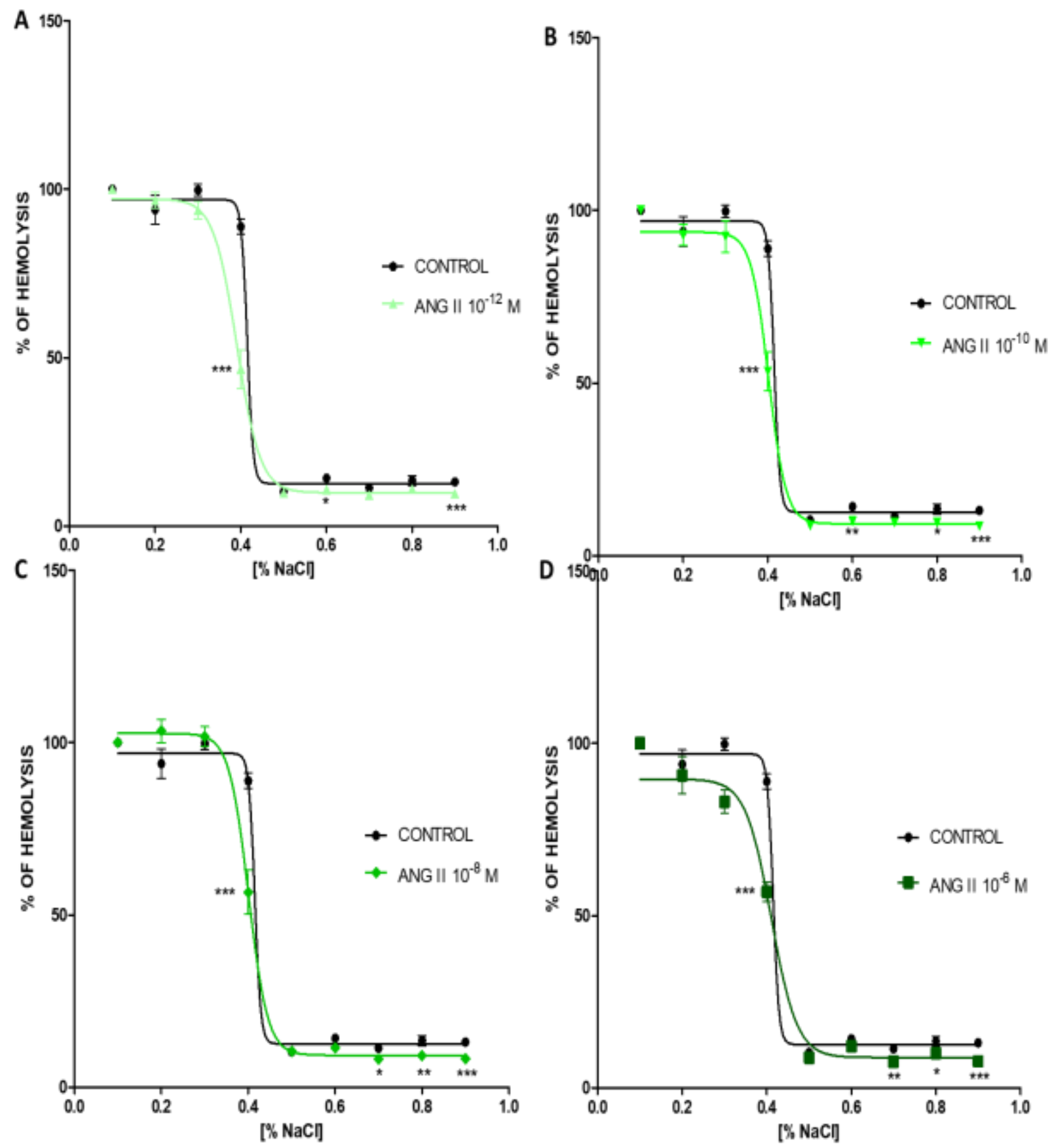

Fig. 1. Osmotic fragility curve of human red blood cells (RBC) treated with Angiotensin II $\left(10^{-6} \mathrm{M}, 10^{-8} \mathrm{M}, 10^{-10} \mathrm{M}, 10^{-12}\right.$ $\mathrm{M})$. Angiotensin $10^{-12} \mathrm{M}(\mathrm{A}), 10^{-10} \mathrm{M}(\mathrm{B}), 10^{-8} \mathrm{M}(\mathrm{C}), 10^{-6} \mathrm{M}$ (D) osmotic fragility curves. Reading was taken in spectrophotometer at $540 \mathrm{~nm}$ absorbance. Ang II stands for angiotensin II. N $=9$ in triplicate. Graphs built by GraphPad Prisma program with mean \pm SEM. $*=\mathrm{p}<0.05, * *=\mathrm{p}<0.01, * * *=\mathrm{p}<0.001$ and $* * * *=\mathrm{p}<0.0001$, vs control, with a $95 \%$ confidence interval in One-way ANOVA and Tukey post-test. 
decrease in hemolysis in all angiotensin II concentrations with losartan $100 \mu \mathrm{M}: 37.94 \%$, $38.16 \%, 20.42 \%$ and $16.22 \%$, respectively as compared to control, mean $93.83 \%$ (Fig. 2). Meanwhile, PD 123319, a classical AT2R antagonist, abolished the protective effect of Ang II against hemolysis (Fig. 3). Thus, demonstrating that the protective effect against hemolysis was made by the AT2 angiotensin II receptor.

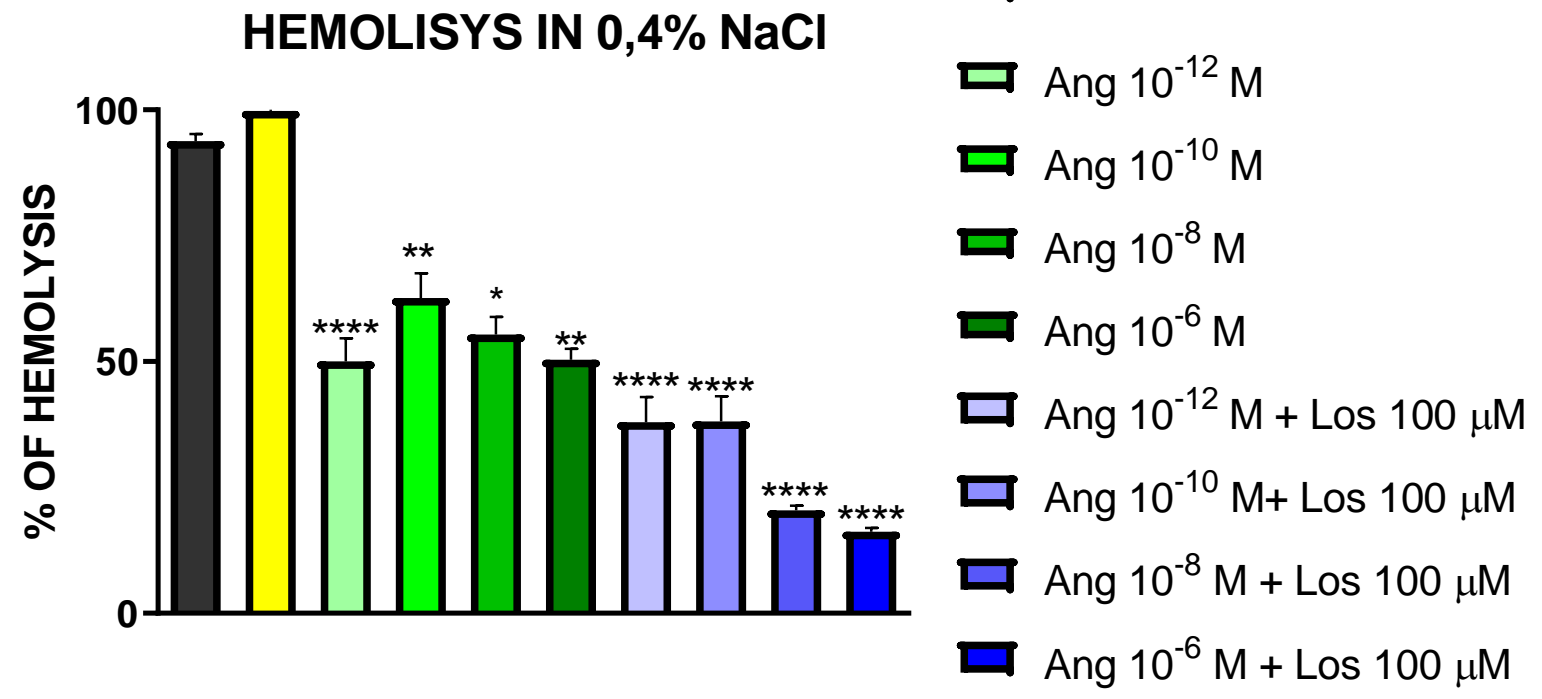

Fig. 2. Osmotic fragility of red blood cells in $\mathrm{NaCl} 0.4 \%$ treated only with Angiotensin II and with Angiotensin II plus losartan $(100 \mathrm{uM})$. Decrease in hemolysis in all Angiotensin II concentrations with losartan. Ang II stands for angiotensin II and LOS stands for losartan. $\mathrm{N}=3$ in triplicate. Values are mean \pm SEM. $*=\mathrm{p}<0.05, * *=\mathrm{p}<0.01, * * *=\mathrm{p}<0.001$ and $* * * *=p<0.0001$ vs control; with a 95\% confidence interval in One-way ANOVA and Tukey post-test.

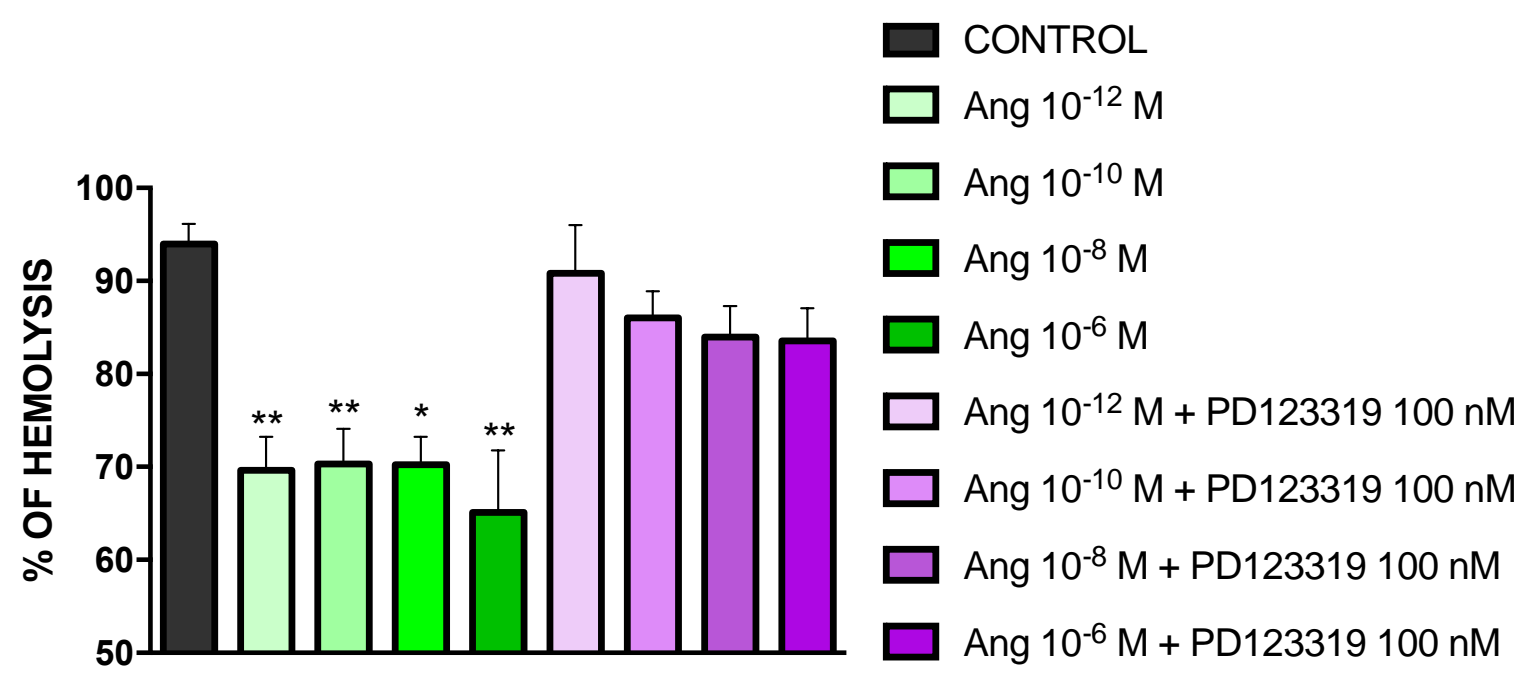

Fig. 3. Osmotic fragility of red blood cells in $\mathrm{NaCl} 0.4 \%$ treated only with Angiotensin II $\left(10^{-6} \mathrm{M}, 10^{-8} \mathrm{M}, 10^{-10} \mathrm{M}, 10^{-12}\right.$ M) and Angiotensin II with PD12319 (100 nM). There was no decrease in hemolysis in Angiotensin II with PD 123319. $\mathrm{N}=3$ in triplicate. Values are mean \pm SEM. $*=\mathrm{p}<0.05$, ** $=\mathrm{p}<0.01$, $* * *=\mathrm{p}<0.001$ and $* * * *=\mathrm{p}<0.0001 \mathrm{vs}$ control; with a $95 \%$ confidence interval in One-way ANOVA and Tukey post-test. 
Considering signaling pathways triggered by hypoosmotic $\mathrm{NaCl} 0.4 \%$, treatment with AICAR, an activator of AMPK, plus angiotensin II and losartan there was no significance of hemolysis when compared those values with the group without AICAR (Fig. 4). Thus, AICAR did not change levels of hemolysis showing that AMPK do not interfere in this pathway through AT2R activation.

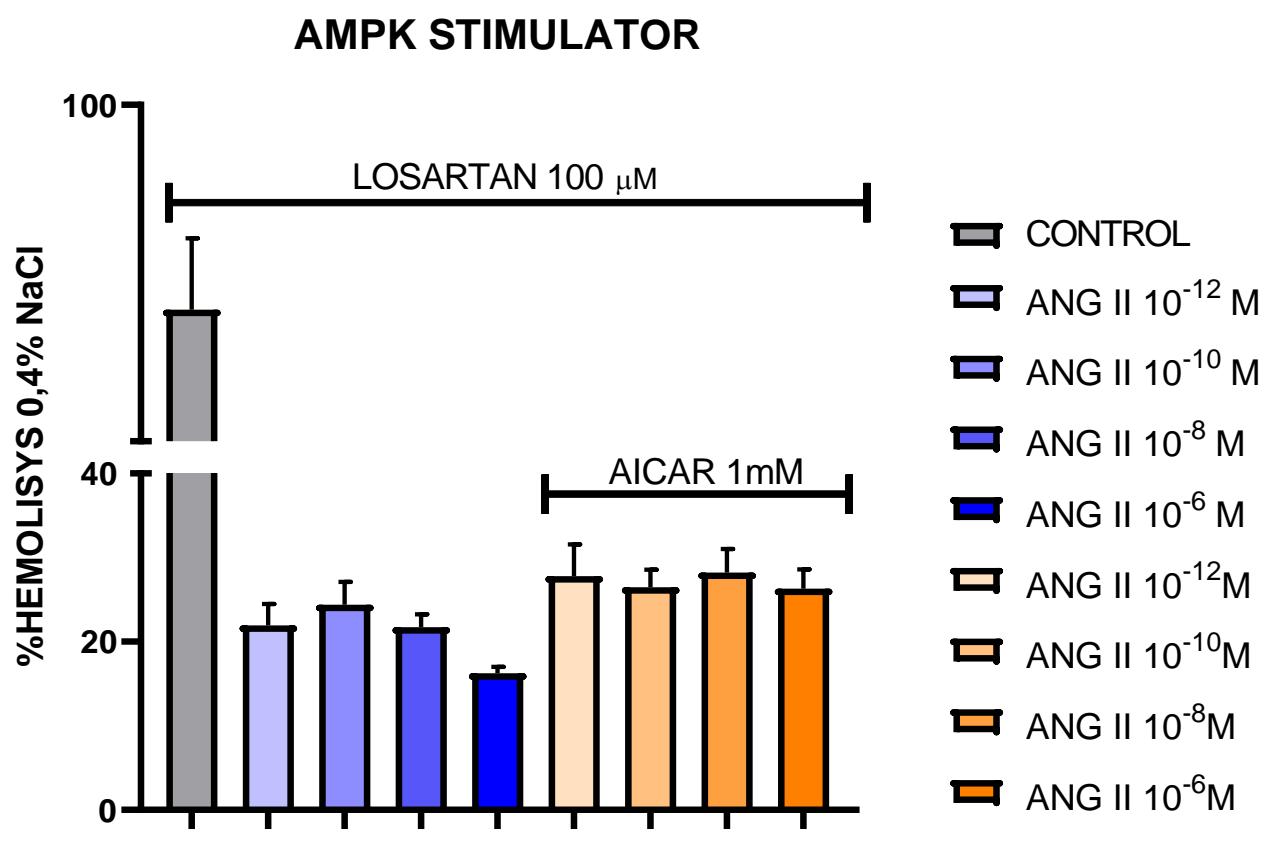

Fig. 4. Osmotic fragility of red blood cells in $\mathrm{NaCl} 0.4 \%$ treated with AICAR ( $1 \mathrm{mM})$ plus Angiotensin II $\left(10^{-6} \mathrm{M}, 10^{-8} \mathrm{M}\right.$, $\left.10^{-10} \mathrm{M}, 10^{-12} \mathrm{M}\right)$ and losartan $(100 \mathrm{uM})$. No significant results was obtained when adding AICAR compared with only Angiotensin II and losartan. The blue bars represent Ang II plus losartan and the orange bars had the addition of AICAR. $\mathrm{N}=3$ in triplicate. Values are mean \pm SEM. $*=\mathrm{p}<0.05$, $* *=\mathrm{p}<0.01, * * *=\mathrm{p}<0.001$ and $* * * *=\mathrm{p}<0.0001$ vs same concentration without AICAR; with a 95\% confidence interval in One-way ANOVA and Tukey post-test.

In order to verify involvement of PI3K/Akt signaling pathway, experiments using Angiotensin II with wortmannin (PI3K inhibitor) and Angiotensin II with AKT inhibitor was performed. There was a total reversion of Ang II effects by Ang II plus wortmannin and losartan $(81,38 \%, 80,58 \%$, $82,54 \%$ and $68,17 \%$ for the four Ang II concentrations, respectively) (Fig. 5), confirming the role played by $\mathrm{PI} 3 \mathrm{~K}$ in hemolysis prevention. Akt inhibitor also displayed similar results, reverting partially the effects of Ang II combined with losartan $(49,80 \%, 41,70 \%, 53.46 \%$ and $46.83 \%$ for the four Ang II concentrations plus Akt inhibitor, respectively) (Fig. 6), also ratifying activation of Akt in protection of hemolysis by Ang II.
Involvement of p38 MAPK was also investigated with SB 202190, a specific inhibitor of this kinase, where the same result pattern for AKT 1/2 inhibitor was found. It is possible to observe a partial reversion in the group treated with angiotensin II, losartan and SB $202190(50.08 \%, 55.50 \%, 53.76 \%$ and $56.37 \%$ for the four Ang II concentrations, respectively) compared with the group treated without SB 202190 (Fig. 7). It is also clear here the role of p38 MAPK in preventing hemolysis, and this protein is probably involved in AT2R signaling pathway.

Analysis using GO 6983, a PKC inhibitor, with angiotensin plus losartan demonstrated that GO 6983 do not revert the action of angiotensin II $(40.13 \%, 37,87 \%, 33,63 \%$, 
$34,40 \%$ for the four Ang II concentrations, respectively) compared with the same experiment without GO 6983 (Fig. 8). This result indicates that there is no involvement of the PKC pathway in the protection of hemolysis.

\section{PI3K INHIBITOR}

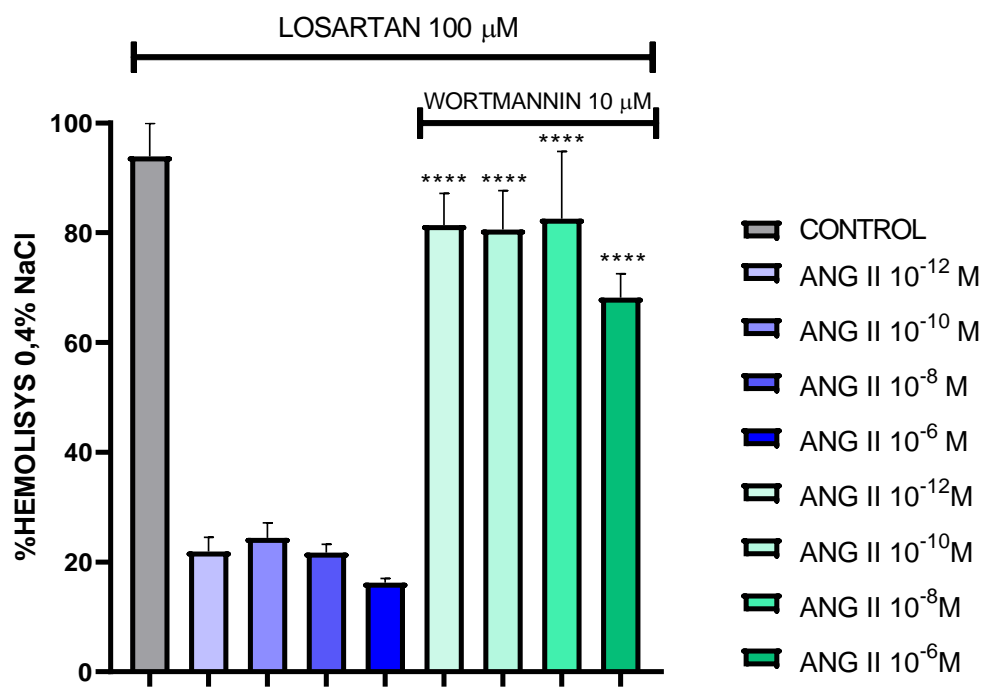

Fig. 5. Osmotic fragility of red blood cells in $\mathrm{NaCl} 0.4 \%$ treated with Wortmannin ( $10 \mathrm{uM})$ plus Angiotensin II $\left(10^{-6} \mathrm{M}\right.$, $\left.10^{-8} \mathrm{M}, 10^{-10} \mathrm{M}, 10^{-12} \mathrm{M}\right)$ and losartan $(100 \mathrm{uM})$. Wortmannin reversed the effect of Angiotensin II plus losartan in all four concentrations protecting erythrocyte from hemolysis. The blue bars represent Ang II plus losartan and the green bars had the addition of Wortmannin. $\mathrm{N}=3$ in triplicate. Values are mean \pm SEM. $*=\mathrm{p}<0.05, * *=\mathrm{p}<0.01, * * *=\mathrm{p}<0.001$ and $* * * *=p<0.0001$ vs same concentration without Wortmannin; with a 95\% confidence interval in One-way ANOVA and Tukey post-test.

\section{AKT INHIBITOR}

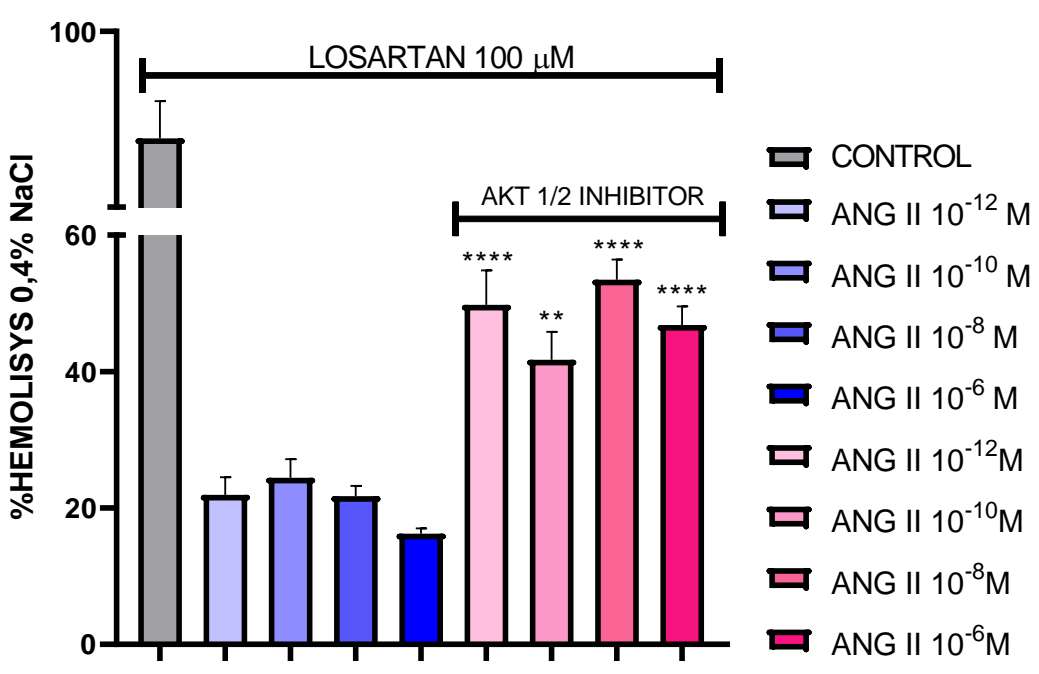

Fig. 6. Osmotic fragility of red blood cells in $\mathrm{NaCl} 0.4 \%$ treated with Akt $1 / 2$ Inhibitor plus Angiotensin II (10-6 M, 10$8 \mathrm{M}, 10-10 \mathrm{M}, 10-12 \mathrm{M}$ ) and losartan. The AKT1/2 inhibitor reversed the effect of Angiotensin II plus losartan in all four concentrations protecting erythrocyte from hemolysis. The blue bars represent Ang II plus losartan and the pink bars had the addition of AKT $1 / 2$ Inhibitor. $\mathrm{N}=3$ in triplicate. Values are mean \pm SEM. $*=\mathrm{p}<0.05, *=\mathrm{p}<0.01, * *=\mathrm{p}<0.001$ and $* *=p<0.0001$ vs same concentration without Akt 1/2 inhibitor; with a 95\% confidence interval in One-way ANOVA and Tukey post-test. 


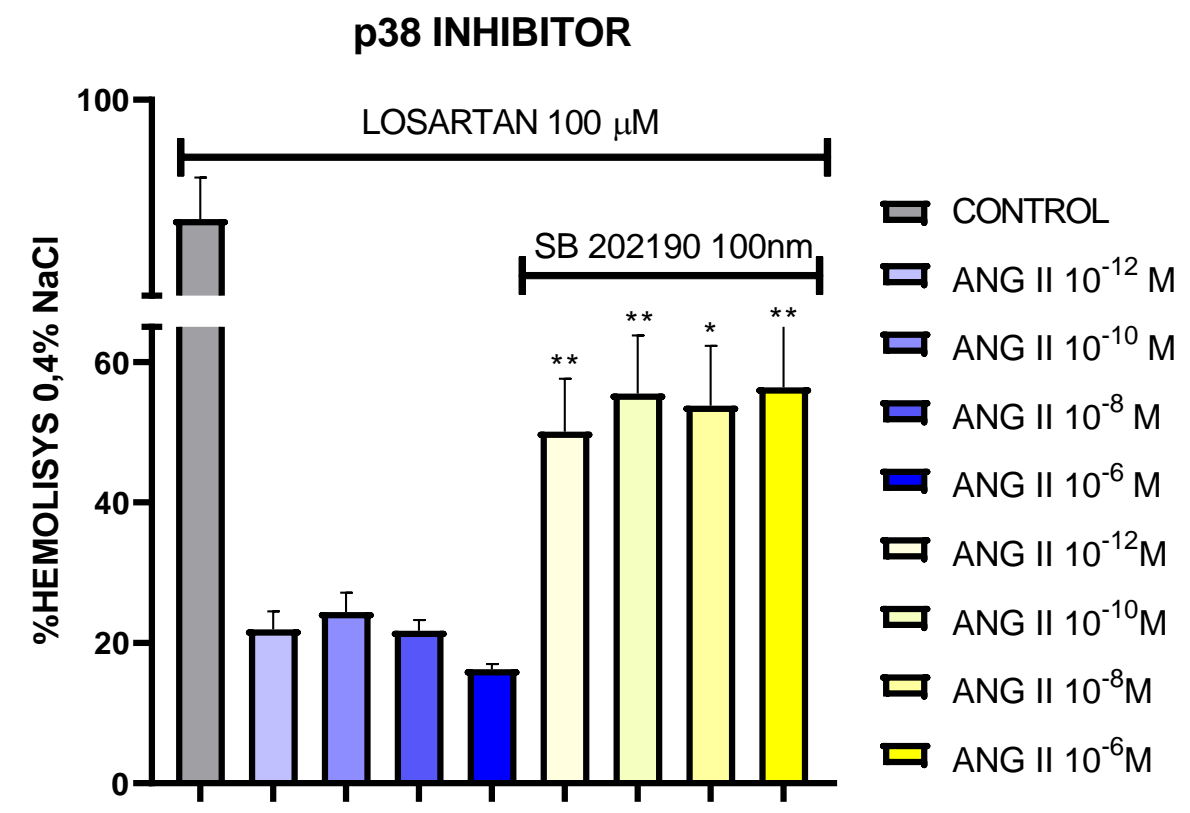

Fig. 7. Osmotic fragility of red blood cells in $\mathrm{NaCl} 0.4 \%$ treated with $\mathrm{SB} 202190$ (100 nM) plus Angiotensin II (10 ${ }^{-6} \mathrm{M}$, $\left.10^{-8} \mathrm{M}, 10^{-10} \mathrm{M}, 10^{-12} \mathrm{M}\right)$ and losartan. SB 202190 reversed the effect of Angiotensin II $\left(10^{-6} \mathrm{M}, 10^{-8} \mathrm{M}, 10^{-10} \mathrm{M}, 10^{-12} \mathrm{M}\right)$ plus losartan, demonstrating a decrease of hemolysis in all four concentrations. The blue bars represent Ang II plus losartan and the yellow bars had the addition of SB $202190 \mathrm{~N}=3$ in triplicate. Values are mean \pm SEM. $*=\mathrm{p}<0.05$, $* *=$ $\mathrm{p}<0.01, * * *=\mathrm{p}<0.001$ and $* * * *=\mathrm{p}<0.0001$ vs same concentration without SB 202190; with a 95\% confidence interval in One-way ANOVA and Tukey post-test.

PKC INHIBITOR

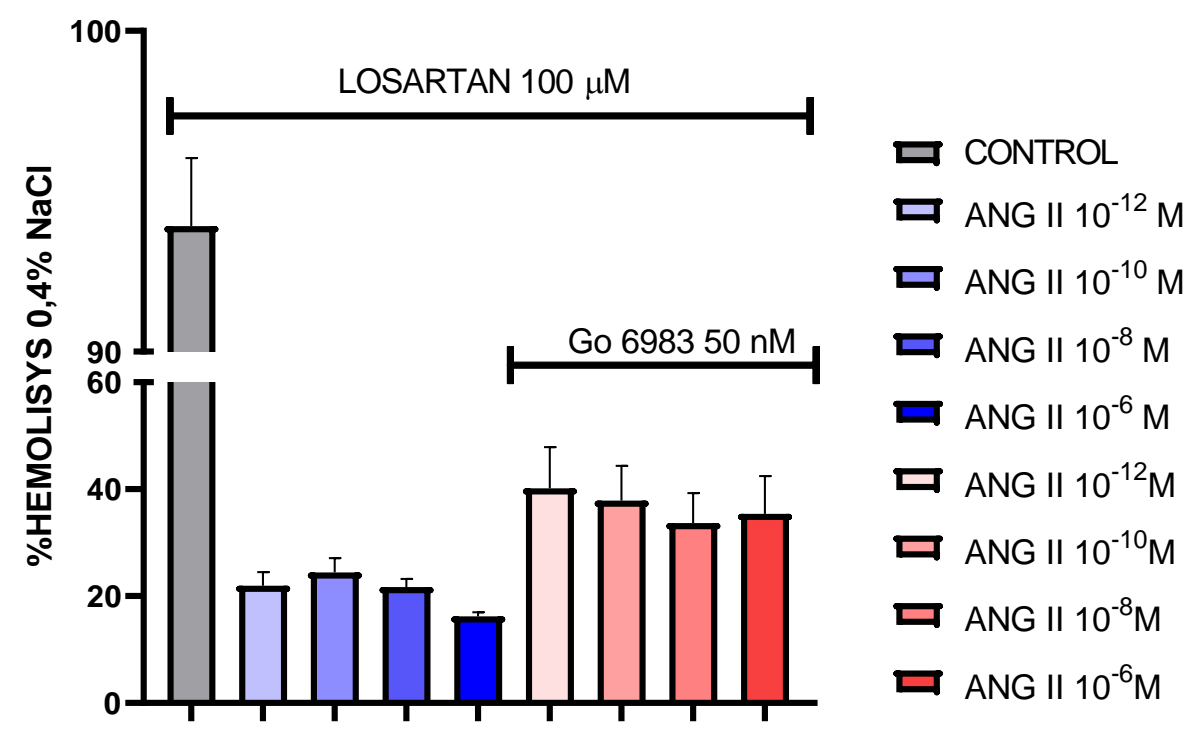

Fig. 8. Osmotic fragility of red blood cells in $\mathrm{NaCl} 0.4 \%$ treated with GO $6983(50 \mathrm{nM})$ plus Angiotensin II $\left(10^{-6} \mathrm{M}, 10^{-8}\right.$ $\left.\mathrm{M}, 10^{-10} \mathrm{M}, 10^{-12} \mathrm{M}\right)$ and losartan. No significant results were obtained when adding Go 6983 compared with only angiotensin II and losartan, therefore no protection against hemolysis occurs through this pathway. The blue bars represent Ang II plus losartan and the red bars had the addition of GO 6983. N=3 in triplicate. Values are mean \pm SEM. $*=p<0.05$, $* *=\mathrm{p}<0.01, * * *=\mathrm{p}<0.001$ and $* * * *=\mathrm{p}<0.0001$ vs same concentration without GO 6983; with a 95\% confidence interval in One-way ANOVA and Tukey post-test. 


\section{Discussion}

Erythrocytes are complex cells with a very tight control of survival, deformability and gas transport. As for its complexity, several mechanisms underlie maintenance of such strength, as also happens in nucleated cells, like intricated intracellular signaling pathway mechanisms. Vona and coworkers (2019) demonstrated the presence of functional estrogen receptors on red blood cells, able to activate ERK, AKT and p38 MAPK (20). Peng et al. (2019) found erythrocyte AMPK as a missing link that promotes oxygen delivery by hemoglobin in a helpful way to prevent and counteract kidney diseases promoted by hypoxia, bringing an interesting new target for treating the disease; this AMPK activation occurred through erythrocyte adenosine surface receptor ADORA2B (21).

In the sense of controlling deformability, much effort is made to keep the cell viable. This involves activation of ion pumps, ion channels, cotransport and many methods are available to measure this deformability, being the osmotic fragility test, one relying on critical erythrocyte volume, with a big application in diagnoses of erythrocyte membrane deformability defects $(22,23)$. Our group already demonstrated the influence of TSH receptors in erythrocyte osmotic fragility (24). In the present work, we applied the technique to evaluate the effect of angiotensin II in erythrocyte volume control and to investigate a possible signaling pathway underneath it. When subjected to several osmotic pressures changing by $\mathrm{NaCl}$ concentrations, Ang II was able to protect erythrocytes from lysis in all four different concentrations used in this study, with an outstanding reduction in hemolysis at $0.4 \%$ $\mathrm{NaCl}$, which was very lytic in control group. Among factors that affects negatively erythrocyte osmotic stability are cholesterol deficiency (25), Plasmodium proteins (26), triglyceride-lowering drug, as cemtirestat (27) and exercise (28). On the other hand, pulsed magnetic field (29), vitamins $\mathrm{C}$ and $\mathrm{D}$ acting against ethanol-induced toxicity (30) and fisetin and probiotic supplementation (31) are positively correlated to erythrocyte osmotic stability. Interestingly, in $\mathrm{NaCl} 0.4 \%$ there was a statistically significantly reduction in hemolysis at all Angiotensin II concentrations pointing that the hormone act on erythrocytes reducing osmotic fragility in osmotic stressed erythrocytes. This is of fundamental importance for erythrocyte physiology since literature reported the relation among sodium $\mathrm{Na}^{+} / \mathrm{K}^{+}$-ATPase activity, erythrocyte deformability and osmotic fragility (32).

Involvement of Ang II receptors was also investigated through the use of pharmacological antagonist losartan and PD 123319, for AT1R and AT2R, respectively, where it is possible to observe lack of AT1R action and the protective effects coming from AT2R activation. It is well documented by literature the presence of angiotensin receptors on erythrocyte surface: presence of Ang-(1-7) MAS receptor was found to regulate erythrocyte invasion by Plasmodium falciparum (33) being this effect mimicked by captopril, an angiotensin-converting enzyme (ACE) inhibitor, drug class also involved in lowering hematocrit by impaired hematopoiesis (34). Erythropoiesis is known to be regulated by AT1 receptor (10) and blocking AT2R with PD 123319 reverted partially the Ang II effects in reducing erythrocyte invasion by $P$. falciparum (9). These studies reveal functionality of Ang II receptors in erythrocytes, with the present study ratifying the importance of these receptors in matters of cell survival and control of osmotic gradient.

As for signaling pathway trigged by Ang II receptors, AMPK was our first approach, based on studies suggesting this enzyme acts downstream ADORA2B receptors and contributes to sickling in sickle cell disease erythrocytes (Liu et al., 2016), regulates eryptosis (36) and helps delivering oxygen from hemoglobin (37). AMPK activation in our model displayed no effect when Ang II was incubated with losartan, showing that AMPK inhibition is not presumably important 
for sustenance of low hemolysis rate in osmotic stress.

PI3K/AKT signaling pathway was also assessed, since this pathway is strongly correlated to erythropoiesis (38), osmopressor stress (39) and modulating red blood cell nitric oxide pathway, rheology and oxidative stress (40). PI3K inhibition led to total reversion of hemolysis, increasing the osmotic resistance, showing that this protein is required for hormone action. In the same way, AKT inhibition also demonstrated the same profile of PI3K inhibition, strongly suggesting downstream effects. This is a remarkable fact since reports in literature also point at AKT phosphorylation as a downstream effect of nitric oxide signaling leading to greater erythrocyte deformability (16).

P38 MAPK involvement was also studied with great reversion above angiotensin II combined with losartan, ratifying it role in ATR2 actions. Several reports bring not only the presence of this MAPK in erythrocytes, but also its role in disruption of erythrocyte membrane (41), erythrocyte shrinkage (42) and eryptosis (36).

On the other hand, PKC inhibition failed to revert hemolysis effects when added together with Ang II plus losartan, which display this pathway as not essential for Ang II actions through ATR2. Silva-Herdade and coworkers (2015) demonstrated the negative effect in erythrocyte deformability after inhibiting PKC (43); similarly, blocking PKC actions by inhibitors showed to impairs erythropoiesis (44) in another model.

Our study shows for the first time the action of Ang II in under hypo-osmotic condition erythrocytes with a substantial decrease in hemolysis in the presence of the hormone. Also, we provide here evidences linking activation of AT2R with downstream signaling pathway involving p38, PI3K and AKT effectors in erythrocytes in order to prevent hemolysis by osmotic stress, as shown in Figure 9.

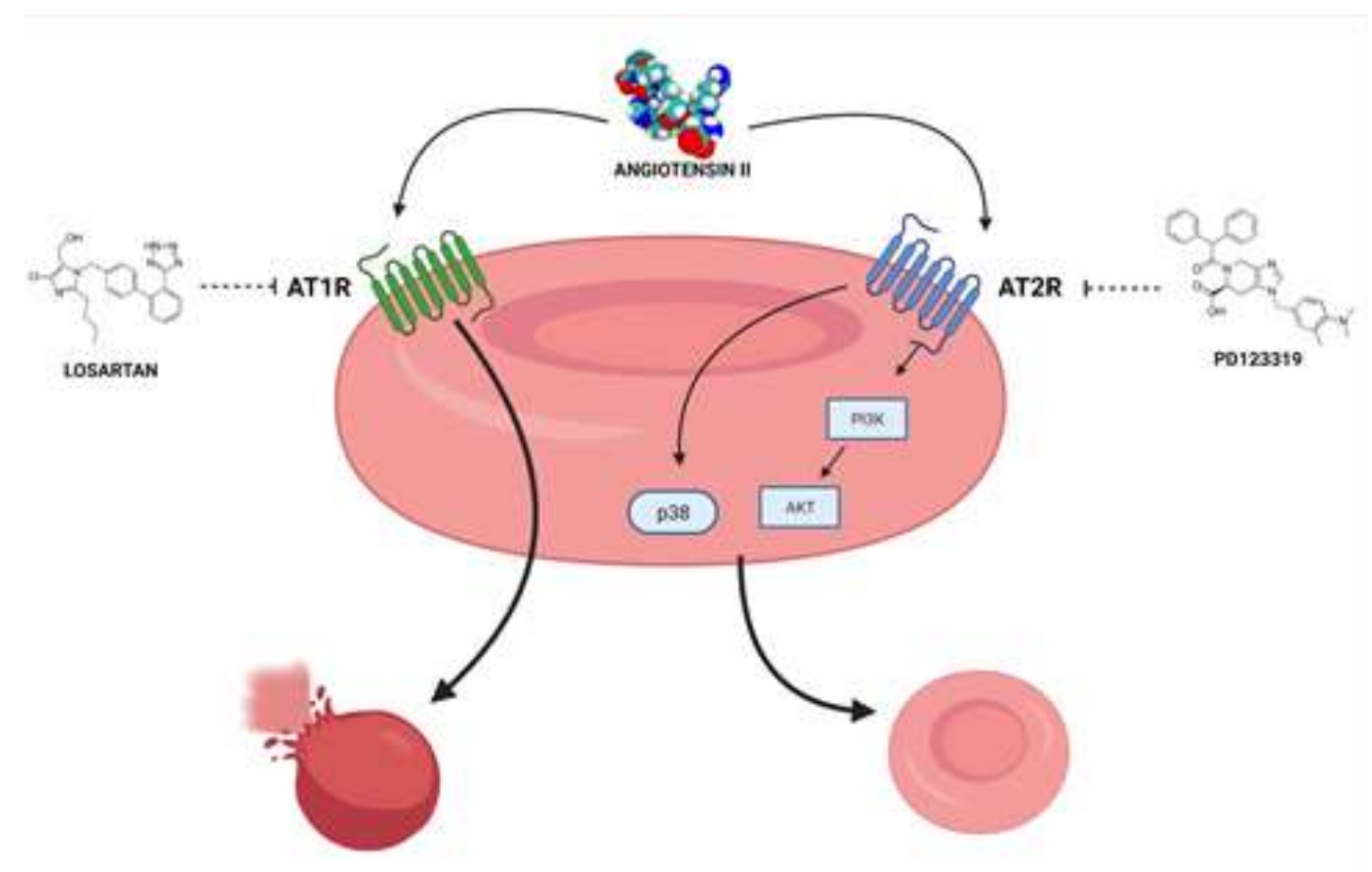

Fig. 9. Representative scheme of the angiotensin II pathway of action in the erythrocyte. Angiotensin II by binding to it AT2 receptor (antagonized by PD 123319) lead to decreased hemolysis which is via p38 and PI3K/Akt signaling pathways. AT1 angiotensin receptor (antagonized by losartan) has no effect on decreased hemolysis (Created with BioRender.com) 


\section{Acknowledgements}

We thank FAPERJ, FUNEMAC, CAPEs and $\mathrm{CNPq}$ for financial support. We also Thank Dr. Juliana Montani Raimundo for kindly donating wortmannin and Akt 1/2 inhibitor.

This study was supported by Fundação Carlos Chagas Filho de Amparo à Pesquisa do Estado do Rio de Janeiro (Edital SediadasFAPERJ, E-26/010.000175/2016), Conselho

\section{References}

1. Turu G, Balla A, Hunyady L. The Role of $\beta$ Arrestin Proteins in Organization of Signaling and Regulation of the AT1 Angiotensin Receptor. Front Endocrinol. 2019;10: 509.

2. Wu C-H, Mohammadmoradi S, Chen JZ, Sawada H, Daugherty A, Lu HS. ReninAngiotensin System and Cardiovascular Functions. Arterioscler Thromb Vasc Biol. 2018;38(7).

3. Wang Y, Fan Y, Song Y, Han X, Fu M, Wang $\mathrm{J}$, et al. Angiotensin II induces apoptosis of cardiac microvascular endothelial cells via regulating PTP1B/PI3K/Akt pathway. In Vitro Cell Dev Biol Anim. 2019;55(10):801-811.

4. Yu Z, Swiercz AP, Moshfegh CM, Hopkins L, Wiaderkiewicz J, Speth RC, et al. Angiotensin II Type 2 Receptor-Expressing Neurons in the Central Amygdala Influence Fear-Related Behavior. Biol Psychiatry. 2019;86(12):899-909.

5. Gao Y, Kang L, Li C, Wang X, Sun C, Li Q, et al. Resveratrol Ameliorates Diabetes-Induced Cardiac Dysfunction Through AT1R-ERK/p38 MAPK Signaling Pathway. Cardiovasc Toxicol. 2016;16(2):130-7.

6. Zhao Y, Chen X, Cai L, Yang Y, Sui G, Fu S. AngiotensinII/angiotensinII type I receptor (AT1R) signaling promotes MCF-7 breast cancer cells survival via PI3-kinase/Aktpathway. J Cell Physiol. 2010;225(1):168-73.

7. Kim N, Jung Y, Nam M, Sun Kang M, Lee MK, Cho Y, et al. Angiotensin II affects inflammation mechanisms via AMPK-related signalling pathways in HL-1 atrial myocytes. Sci Rep. 2017;7(1):10328.

8. Zhang H, Unal H, Desnoyer R, Han GW, Patel

$\mathrm{N}$, Katritch V, et al. Structural Basis for
Nacional de Desenvolvimento Científico (CNPq, PQ- Nível 2, 305872/2016-8) and Coordenação de Aperfeiçoamento de Pessoal de Nível Superior (CAPES/Ciências sem Fronteiras/PVE/88881.062218/2014-0), who supported the scholarship. Funders had no role in the study design, data collection and analysis, decision to publish, or preparation of the manuscript.

Ligand Recognition and Functional Selectivity at Angiotensin Receptor. J Biol Chem. 2015;290(49):29127-39.

9. Saraiva VB, de Souza Silva L, FerreiraDaSilva CT, da Silva-Filho JL, Teixeira-Ferreira A, Perales J, et al. Impairment of the Plasmodium falciparum erythrocytic cycle induced by angiotensin peptides. PLoS One. 2011;6(2):e17174.

10. Kato H, Ishida J, Matsusaka T, Ishimaru T, Tanimoto K, Sugiyama F, et al. Erythropoiesis and Blood Pressure Are Regulated via AT1 Receptor by Distinctive Pathways. PloS One. 2015;10(6):e0129484.

11.Kim Y-C, Mungunsukh O, Day RM. Erythropoietin Regulation by Angiotensin II. Vitam Horm. 2017;105:57-777.

12. Roeloffzen WWH, Kluin-Nelemans HC, Bosman L, de Wolf JTM. Effects of red blood cells on hemostasis. Transfusion. 2010;50(7):1536-44.

13. Schmidt HHHW, Feelisch M. Red Blood Cell-Derived Nitric Oxide Bioactivity and Hypoxic Vasodilation. Circulation. 2019;139(23):2664-2667.

14. Semenov AN, Shirshin EA, Muravyov AV, Priezzhev AV. The Effects of Different Signaling Pathways in Adenylyl Cyclase Stimulation on Red Blood Cells Deformability. Front Physiol. 2019;10.

15. Zhang Y, Dai Y, Wen J, Zhang W, Grenz A, Sun $\mathrm{H}$, et al. Detrimental effects of adenosine signaling in sickle cell disease. Nat Med. 2011;17(1):79-86.

16. Kuck L, Grau M, Bloch W, Simmonds MJ. Shear Stress Ameliorates Superoxide Impairment 
to Erythrocyte Deformability with Concurrent Nitric Oxide Synthase Activation. Front Physiol. 2019;10:36.

17. Sugie J, Intaglietta M, Sung LA. Water transport and homeostasis as a major function of erythrocytes. Am J Physiol Heart Circ Physiol. 2018;314(5):H1098-107.

18. Ana Carla Caires, Miriane da Costa Gileno Padronização e Aplicação da Curva de Fragilidade Osmótica no Auxílio Diagnóstico de Anemias. Brazilian Multidisciplinary Journal. 2012;5 (2):49-58.

19. Bianchi P, Fermo E, Vercellati C, Marcello AP, Porretti L, Cortelezzi A, et al. Diagnostic power of laboratory tests for hereditary spherocytosis: a comparison study in 150 patients grouped according to molecular and clinical characteristics. Haematologica. 2012;97(4):51623.

20. Vona R, Gambardella L, Ortona E, Santulli M, Malorni W, Carè A, et al. Functional Estrogen Receptors of Red Blood Cells. Do They Influence Intracellular Signaling? Cell Physiol Biochem Int J Exp Cell Physiol Biochem Pharmacol. 2019;53(1):186-99.

21. Peng Z, Luo R, Xie T, Zhang W, Liu H, Wang W, et al. Erythrocyte Adenosine A2B ReceptorMediated AMPK Activation: A Missing Component Counteracting CKD by Promoting Oxygen Delivery. J Am Soc Nephrol JASN. 2019;30(8):1413-24.

22. Emilse LAM, Cecilia H, María TM, Eugenia MM, Alicia IB, Lazarte SS. Cryohemolysis, erythrocyte osmotic fragility, and supplementary hematimetric indices in the diagnosis of hereditary spherocytosis. Blood Res. 2018;53(1):10-7.

23. Huisjes R, Bogdanova A, van Solinge WW, Schiffelers RM, Kaestner L, van Wijk R. Squeezing for Life - Properties of Red Blood Cell Deformability. Front Physiol. 2018;9:656.

24. Mendonça-Reis E, Mendonça-Reis E. Effects of TSH on Erythrocyte Osmotic Fragility: Signaling Pathway. International Journal of Blood Research and Disorders. 2020;7(1):1-7.

25. Bernecker C, Köfeler H, Pabst G, Trötzmüller M, Kolb D, Strohmayer K, et al. Cholesterol Deficiency Causes Impaired Osmotic
Stability of Cultured Red Blood Cells. Front Physiol. 2019;10:1529.

26. Peng Y-C, Qi Y, Zhang C, Yao X, Wu J, Pattaradilokrat $\mathrm{S}$, et al. Plasmodium yoelii Erythrocyte-Binding-like Protein Modulates Host Cell Membrane Structure, Immunity, and Disease Severity. mBio. 2020;11(1):e02995-19. 27.

Prnova MS, Kovacikova L, Svik K, Bezek S, Elmazoğlu Z, Karasu C, et al. Triglyceridelowering effect of the aldose reductase inhibitor cemtirestat-another factor that may contribute to attenuation of symptoms of peripheral neuropathy in STZ-diabetic rats. Naunyn Schmiedebergs Arch Pharmacol. 2020; 393(4):651-661.

28. Lippi G, Sanchis-Gomar F. Epidemiological, biological and clinical update on exercise-induced hemolysis. Ann Transl Med. 2019;7(12):270.

29. Ahn H, Shin K, Lee H. Effects of Pulsed Magnetic Field on the Hemolysis of Erythrocytes Exposed to Oxidative Stress. Adv Exp Med Biol. 2020;1232:263-269.

30. Hasanein $P$, Mohammadi-Raighan $P$, Komaki A. Vitamins $\mathrm{C}$ and $\mathrm{E}$ alone and in combination partly protect against chronic ethanol-induced toxicity in rat erythrocytes. Int J Vitam Nutr Res. 2019;89(3-4):152-160.

31. Ogbuagu NE, Aluwong T, Ayo JO, Sumanu VO. Effect of fisetin and probiotic supplementation on erythrocyte osmotic fragility, malondialdehyde concentration and superoxide dismutase activity in broiler chickens exposed to heat stress. J Vet Med Sci. 2018;80(12):1895-900. 32. Santander VS, Campetelli AN, Monesterolo $\mathrm{NE}$, Rivelli JF, Nigra AD, Arce CA, et al. Tubulin-Na+, $\mathrm{K}$ +-ATPase interaction: Involvement in enzymatic regulation and cellular function. J Cell Physiol. 2019;234(6):7752-7763. 33. Silva L de S, Peruchetti D de B, Silva CTFD, Ferreira-DaSilva AT, Perales J, Caruso-Neves $\mathrm{C}$, et al. Interaction between bradykinin B2 and Ang-(1-7) Mas receptors regulates erythrocyte invasion by Plasmodium falciparum. Biochim Biophys Acta. 2016;1860(11, Pt A):2438-2444. 34. Marathias KP, Agroyannis B, Mavromoustakos T, Matsoukas J, Vlahakos DV. Hematocrit-lowering effect following inactivation of renin-angiotensin system with angiotensin converting enzyme inhibitors and 
angiotensin receptor blockers. Curr Top Med Chem. 2004;4(4):483-6.

35. Liu H, Zhang $\mathrm{Y}$, Wu H, D'Alessandro A, Yegutkin GG, Song A, et al. Beneficial Role of Erythrocyte Adenosine A2B Receptor-Mediated AMP-Activated Protein Kinase Activation in High-Altitude Hypoxia. Circulation. 2016;134(5):405-21.

36. Lang E, Lang F. Mechanisms and pathophysiological significance of eryptosis, the suicidal erythrocyte death. Semin Cell Dev Biol. 2015;39:35-42.

37. Sun K, Liu H, Song A, Manalo JM, D'Alessandro A, Hansen KC, et al. Erythrocyte purinergic signaling components underlie hypoxia adaptation. J Appl Physiol (1985). 2017;123(4):951-956.

38. Jafari M, Ghadami E, Dadkhah T, AkhavanNiaki H. PI3k/AKT signaling pathway: Erythropoiesis and beyond. J Cell Physiol. 2019;234(3):2373-2385.

39. Chu Y-H, Lu C-C, Lin T-C, Tsou M-Y, Hsu Y-J, Ho S-T, et al. The Osmopressor-Induced Angiopoietin-1 Secretion in Plasma and Subsequent Activation of the Tie-2/Akt/eNOS Signaling Pathway in Red Blood Cell. Am J Hypertens. 2017;30(3):295-303.
40. Nader E, Grau M, Fort R, Collins B, Cannas G, Gauthier A, et al. Hydroxyurea therapy modulates sickle cell anemia red blood cell physiology: Impact on RBC deformability, oxidative stress, nitrite levels and nitric oxide synthase signalling pathway. Nitric Oxide. 2018;81:28-35.

41. Alfhili MA, Weidner DA, Lee M-H. Disruption of erythrocyte membrane asymmetry by triclosan is preceded by calcium dysregulation and p38 MAPK and RIP1 stimulation. Chemosphere. 2019;229:103-111.

42. Peter T, Bissinger R, Lang F. Erythrocyte Shrinkage and Cell Membrane Scrambling after Exposure to the Ionophore Nonactin. Basic Clin Pharmacol Toxicol. 2016;118(2):107-12.

43. Silva-Herdade AS, Freitas T, Almeida JP, Saldanha C. Erythrocyte deformability and nitric oxide mobilization under pannexin-1 and PKC dependence. Clin Hemorheol Microcirc. 2015;59(2):155-62.

44. Zhou X, Wang S, Zheng M, Kuver A, Wan $\mathrm{X}$, Dai K, et al. Phosphorylation of ELAVL1 (Ser219/Ser316) mediated by PKC is required for erythropoiesis. Biochim Biophys Acta Mol Cell Res. 2019;1866(2):214-224. 